\title{
Prevalence and antimicrobial susceptibility pattern of methicillin resistant Staphylococcus aureus in Silchar Medical College and Hospital, Assam, India
}

\author{
Devarsi Choudhury*, Pinaki Chakravarty
}

\author{
Silchar Medical College and \\ Hospital, Assam, India \\ Received: 21 July 2016 \\ Accepted: 28 August 2016 \\ *Correspondence to: \\ Dr. Devarsi Choudhury, \\ Email: drdevarsi@gmail.com \\ Copyright: (C) the author(s), \\ publisher and licensee Medip \\ Academy. This is an open- \\ access article distributed under \\ the terms of the Creative \\ Commons Attribution Non- \\ Commercial License, which \\ permits unrestricted non- \\ commercial use, distribution, \\ and reproduction in any \\ medium, provided the original \\ work is properly cited.
}

\begin{abstract}
Background: Methicillin resistant staphylococcus aureus (MRSA) strains, usually resistant to several antibiotics, is a cause of concern in many countries. This study determines the prevalence and antimicrobial susceptibility pattern of MRSA in Silchar Medical College and Hospital (SMCH), Assam.

Methods: This retrospective was conducted from January 2014 to June 2015 (1 year and 6 months) in SMCH, Assam. Four samples seen were blood, urine, pus and ear swab. Screening and confirmation of MRSA isolates were done by standard methods recommended by Clinical and laboratory standards institute (CLSI). Staphylococcus aureus strains were tested for Methicillin resistance by using oxacillin/ cefoxitin. The antibiotic susceptibility pattern of all MRSA strain was determined by Kirby-Bauer disc diffusion method.

Results: Out of 724 positive staphylococcus strains, MRSA accounted for 311 cases $(42.96 \%)$. Highest percentage of MRSA cases were from blood culture $(61.68 \%)$. MRSA cases even showed resistance to other antibiotics like cefuroxime, amoxicillin and clavulanic acid, getamicin, levofloxacin, ciprofloxacin, ceftriaxone, nitrofurantoin, amikacin, and vancomycin. 59.50\% cases of MRSA cases showed resistance to cefuroxime. Even Methicillin sensitive strains of staphylococcus Aureus (MSSA) showed resistance to antibiotics like cefuroxime and amoxicillin and clavulanic acid.

Conclusions: The worst feature of MRSA is simultaneous drug resistance to many antibiotics. Measures preventing the spread of MRSA are to be enhanced as fewer options are available for treating MRSA. Hospital guidelines for proper antibiotics usage should be followed.
\end{abstract}

Keywords: MRSA, Staphylococcus aureus, Resistance, Susceptibility, Cefuroxime

\section{INTRODUCTION}

Staphylococcus aureus are commonly found on the skin and/or in the noses of healthy people. Though non-toxic at these sites, it may get into the body (e.g. through breaks in the skin such as abrasions, cuts, wounds, surgical incisions or indwelling catheters) and cause infections. ${ }^{1}$

Methicillin-resistant Staphylococcus aureus (MRSA) were first reported in the early 1960's and are now regarded as a major hospital acquired pathogen worldwide. The term methicillin resistant is historically used to explain resistance to any of this class of antimicrobials. $^{2}$ It is one of the most common causes of hospital-acquired infection all over the world. Carriage of MRSA in nose, axilla, perineum and hand of patients and health care personnel (HCPs), prolonged duration of hospital stay, intravenous drug abuse and irrational use or over-prescription of antibiotics are important risk factors for MRSA acquisition. These factors along with the diversity in mecA gene (responsible for resistant mechanisms of MRSA isolates) pose a major challenge to prevent the spread of disease in both community and hospitals. ${ }^{3}$

The major reservoirs of Staphylococci in hospitals are colonized/ infected in-patients and colonized hospital workers. Transient hand carriage of the organism by healthcare workers account for the major factor for patient to patient transmission. Constant monitoring of these strains is essential in order to control their spread in the hospital setting and spread to the community. ${ }^{4}$ It is very essential to know the prevalence of MRSA in any 
location, because of the public health importance and the threat posed by MRSA infection.

Hence the present study has been undertaken to find out the prevalence and antimicrobial susceptibility pattern of MRSA from clinical samples in Silchar Medical College and Hospital, Assam (SMCH).

\section{METHODS}

The present study was a retrospective study. Before initiating the study, proper approval was taken from the Institutional Ethical Committee (IEC) and the Chief Superintendent of Silchar Medical College and Hospital. It was conducted at SMCH, Assam. The data were collected and analyzed from January 2014 to June 2015 (1 year and 6 months). The template included the following:

Table 1: Template for conducting the study.

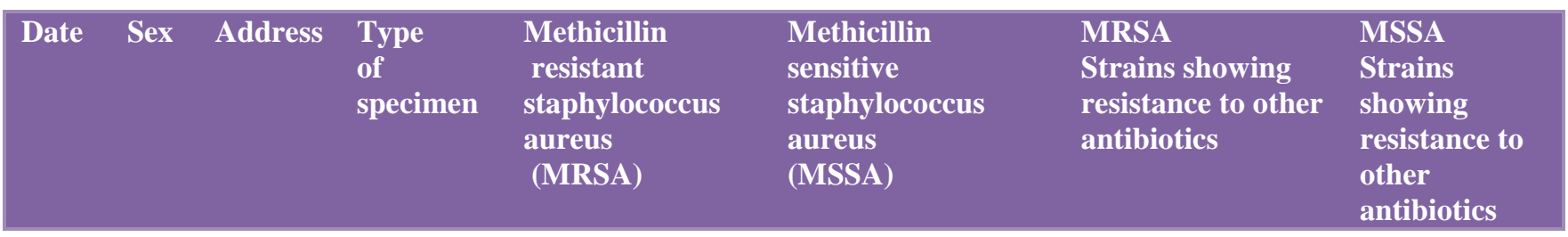

The antibiotic susceptibility testing was performed at the Microbiology department SMCH by using the Kirby Bauer's' disc diffusion technique following Clinical and Laboratory Standards Institute (CLSI) recommendations. ${ }^{5}$ Cefoxitin $(30 \mu \mathrm{g})$ or oxacillin (1ug) were used for methicillin resistance detection. ${ }^{5}$ The Isolates using oxacillin were considered methicillin-resistant if the zone of inhibition was $10 \mathrm{~mm}$ or less. Isolates using cefoxitin disk diffusion showing an inhibition zone diameter of $<19 \mathrm{~mm}$ was considered as methicillin resistant and $>20$ $\mathrm{mm}$ was considered as methicillin sensitive.

The other antibiotics were also tested. They are cefuroxime, amoxicillin and clavulanic acid, gentamicin, levofloxacin, ciprofloxacin, ceftriaxone, nitrofurantoin, amikacin, vancomycin and linezolid. The data thus obtained was recorded and analyzed by using appropriate statistical methods.

\section{RESULTS}

Table 1: Percentage of MRSA strains' presence within the clinical specimens.

\begin{tabular}{|llll|}
\hline $\begin{array}{l}\text { Clinical } \\
\text { specimens }\end{array}$ & $\begin{array}{l}\text { Staphylococci } \\
\text { strains }\end{array}$ & MRSA & $\%$ \\
\hline Blood & 167 & 103 & 61.68 \\
\hline Urine & 163 & 86 & 52.76 \\
\hline Pus & 226 & 122 & 35.06 \\
\hline Ear swab & 46 & 0 & 0 \\
\hline
\end{tabular}

Altogether total specimens seen were 4823. Out of them staphylococci strains detected by standard tests were 724 . Among them the strains showing resistance to methicillin (MRSA) were $311(42.96 \%)$. Thus the cases of Methicillin sensitive staphylococcus (MSSA) came out to be $413(57.04 \%)$. Within the MRSA strains male predominance was seen $(58.78 \%)$. In case of MSSA strains male predominance was slightly less $(50.88 \%)$.

Table 2: Comparison of resistance to antibiotics: MRSA v/s MSSA.

\begin{tabular}{|l|l|l|}
\hline Antibiotics & $\begin{array}{l}\% \text { of MRSA } \\
\text { showing } \\
\text { resistance }\end{array}$ & $\begin{array}{l}\text { \% of MSSA } \\
\text { showing } \\
\text { resistance }\end{array}$ \\
\hline Cefuroxime & 59.50 & 8.96 \\
\hline $\begin{array}{l}\text { Amoxicillin and } \\
\text { Clavulanic acid }\end{array}$ & 34.40 & 15.74 \\
\hline Gentamicin & 24.73 & 2.91 \\
\hline Levofloxacin & 20.43 & 5.8 \\
\hline Ciprofloxacin & 20.07 & 12.59 \\
\hline Ceftriaxone & 9.68 & 0 \\
\hline Nitrofurantoin & 8.22 & 11.11 \\
\hline Amikacin & 4.66 & 2.42 \\
\hline Vancomycin & 0.71 & 0 \\
\hline Linezolid & 0.71 & 0 \\
\hline
\end{tabular}

The prevalence of staphylococcus aureus was seen to significantly vary among the different clinical specimens. They are given in Table 1. Overall the highest number of MRSA cases was seen from the pus sample (39.23\%). The blood samples reported that among its samples showing positive staphylococci strains, the presence of MRSA strains was high (61.68\%). Most of these cases were from the Intensive care unit (ICU) (63\%). The urine specimens even showed a large number of MRSA strains $(52.76 \%)$. Urine specimens were mostly collected from the medicine department. No MRSA cases were seen from the ear swab specimens during the study period. 
It is also noteworthy that MRSA strains showed higher resistance to other group of antibiotics when compared to MSSA strains. For example in Table II, 59.4\% of MRSA strains showed resistance to cefuroxime whereas it was only $8.96 \%$ of MSSA strains that exhibited cefuroxime resistance. Vancomycin and linezolid resistance was $0.71 \%$ in MRSA strains. MSSA cases reported no resistance for ceftriaxone, vancomycin and linezolid.

\section{DISCUSSION}

In India, the importance of MRSA had been accepted relatively late and it emerged as a problem in the 80 s and in the 90s. ${ }^{6}$ MRSA has been associated with significant morbidity and mortality and is a chief public health issue worldwide. In developing nations such as ours, the data relating to MRSA's transmission dynamics still remain unsatisfactory. ${ }^{7}$ A study by Bilal Ahmed et al. reported MRSA strains to be $32 \% .^{8}$ A study by LK Khanal and BK Jha accounted MRSA cases to be $68 \%$. $^{9}$ A study by Dr. SK Kulkarni gave facts which showed MRSA cases even went up to $70.33 \%$. ${ }^{6}$ The research work by Sangeeta et al reported that overall MRSA prevalence was $42 \%$ in 2008 and 40 per cent in $2009 .{ }^{10}$ Our study stated that MRSA accounted $42.96 \%$ of the staphylococci cases, which showed it was almost following the similar trend with the rest of the country. A study by Karem $\mathrm{H}$. Alzoubi in Jordan reported the overall prevalence of MRSA to be $34 \%$, which was considered alarming as it was a newly established hospital. ${ }^{11}$ It mentioned that the highest number of cases belonged to the ICU units $(57.6 \%)$. Even in our study we found out that a large percentage of the MRSA cases were from the ICU (63\%).

A study by Anurupa et al in 2003 declared that maximum isolation of MRSA was from pus and wound swabs (52.5). ${ }^{12}$ The study by Ankur Goyal et al revealed out of all MRSA isolates, the highest prevalence was observed in pus samples $(66.03 \%)$ followed by urine $(11.45 \%)$ and blood and tips $(9.16 \%)$. The article by Sangeeta et al said that overall MRSA strains was highest for skin and soft tissue infections (64\% in 2008 and $61 \%$ in 2009) followed by blood (48\%) and respiratory samples including bronchial washings, endotracheal secretions and sputum $(41 \%) .{ }^{10}$ A study by Purav Patel et al in a tertiary care teaching hospital, Western India also found out that skin and soft tissue infection (72.37) accounted for most of the MRSA cases. ${ }^{1}$ Our study revealed that the highest number of specimens accounting for MRSA strains were from the pus samples followed by blood and the urine specimens.

The pattern of antibiotic resistance also follows a similar trend. Resistance to other antibiotics was encountered more in MRSA strains in comparison to MSSA strains. The study by Purav et al showed that hospital acquired MRSA strains showed high resistance to gentamicin $(61.54 \%)$. The study by Aslam et al found that the MRSA strains were resistant to cefazolin and augmentin. ${ }^{13}$ In the study by Javid A Dar, among the 61 strains of MRSA, 56 strains were found resistant to other group of antibiotics. ${ }^{4}$ The research work by M Prakash revealed that the highest resistance showed by MRSA isolates was 38.10 percent against levofloxacin. All the other antibiotics which were tested in this study, i.e., ciprofloxacin, erythromycin, streptomycin and levofloxacin exhibited a sensitivity range of 62.0 to 82.0 percent. ${ }^{14}$ Likewise our study showed resistance to the other antibiotics to a level of $60 \%$. It is worth mentioning that the MRSA strains in our study showed resistance to vancomycin and linezolid $(0.71 \%)$.

\section{CONCLUSION}

The standard monitoring of antimicrobial susceptibility pattern of MRSA and creation of a definite antimicrobial policy may be helpful for stopping the numbers of these infections in the hospitals. Additional confirmatory study can be done by detection of mecA gene by PCR method, which is measured as the gold standard. This study also affirms the importance of proper usage of the antibiotics by the health care professionals in the hospital so as to prevent the antibiotics resistance.

\section{ACKNOWLEDGEMENTS}

We are grateful to the working staff of Microbiology dept. SMCH for helping us in carrying the study in the best possible way.

\section{Funding: No funding sources}

Conflict of interest: None declared

Ethical approval: The study was approved by the Institutional Ethics Committee

\section{REFERENCES}

1. Patel P, Khandelwal N, Raval P, Patel B, Soni S, Vegad M. Prevalence And Antimicrobial Susceptibility Pattern Of Methicillin Resistant Staphylococcus Aureus In Tertiary Care Teaching Hospital, Western India. Int J Med Sci Public Health. 2014;3(1):58-60.

2. Biswajit BB, Kundu GKR, Biswas S. Methicillin Resistant Staphylococcus aureus: A Brief Review. International Research Journal of Biological Sciences. 2012;1(7):65-71.

3. Singh AK, Gupta M, Agarwal A, Gupta P, Singh M. Prevalence of Methicillin-Resistant Staphylococcus aureus colonization and its antibiotic susceptibility profile among healthcare personnel in a tertiary care setup of northern India. Int J Curr Microbiol App Sci. 2013;2(10):293-9.

4. Dar JA, Thoker MA, Khan JA, Ali A, Khan MA, Rizwan M, et al. Molecular epidemiology of clinical and carrier strains of Methicillin resistant Staphylococcus aureus (MRSA) in the hospital settings of north India. Annals of Clinical Microbiology and Antimicrobials. 2006;5(22):1-15. 
5. Performance standards for antimicrobial susceptibility testing; Twenty-second informational supplement. 2012:88-9.

6. Kulkarni S, Khare A, Kaur DC. Prevalence of Methicillin Resistant Staphylococcus aureus: A study in a tertiary care rural hospital. Indian Journal of Basic and Applied Medical Research. 2014;3(3):41421.

7. Ray P, Singh R. Methicillin-resistant Staphylococcus aureus carriage screening in intensive care. Indian $\mathbf{J}$ Crit Care Med. 2013;17(4):205-6.

8. Mir BA, Srikanth. Prevalence and antimicrobial susceptibility of Methicillin Resistant Staphylococcus aureus and Coagulase-negative staphylococci in a tertiary care hospital. Asian J Pharm Clin Res. 2013;6(3):231-4.

9. Khanal LK, Jha BK. Prevalence of Methicillin resistant Staphylococcus aureus (MRSA) among skin infection cases at a hospital in Chitwan, Nepal. Nepal Med Coll J. 2010;12(4):224-8.

10. Indian Network for Surveillance of Antimicrobial Resistance (INSAR) group, India. Methicillin resistant Staphylococcus aureus (MRSA) in India:
Prevalence and susceptibility pattern. Indian J Med Res. 2013;137:363-9.

11. Alzoubi KH, Hayajneh WA, Ayoub AM, Al-Safi SA, A-Azzam SI, Mhaidat NM. Prevalence of Methicillin-resistant Staphylococcus aureus (MRSA) at a Tertiary Hospital in North Jordan. Jordan Journal of Pharmaceutical Sciences. 2010;3(1):37-43.

12. Anupurba S, Sen MR, Nath G, Sharma BM, Gulati AK, Mohapatra TM. Prevalence of MethicillinResistant Staphylococcus aureus in a Tertiary Referral Hospital in Eastern Uttar Pradesh. Indian J Med Microbiol. 2003;21:49-51.

13. Aslam M, Khan M, Ahmad S, Sharma L. Current trend of antimicrobial susceptibility pattern of Methicillin resistant staphylococcus aureus isolated from tertiary care Hospital Delhi NCR region India. IJRAP. 2011;2(4):1339-42.

14. Prakash M, Rajasekar K and Karmegam N. Prevalence of Methicillin Resistant Staphylococcus aureus in Clinical Samples Collected from Kanchipuram Town, Tamil Nadu, South India. J Appl Sci Res. 2007;3(12):1705-9.

Cite this article as: Choudhury D, Chakravarty P. Prevalence and antimicrobial susceptibility pattern of methicillin resistant Staphylococcus aureus in Silchar Medical College and Hospital, Assam, India. Int J Basic Clin Pharmacol 2016;5:2174-7. 